\title{
A Diagnostic Dilemma for Acute Abdomen: Sclerosing Encapsulating Peritonitis (Abdominal Cocoon Syndrome); A Retrospective Cohort Study
}

\author{
Mehmet Buğra Bozan, MD; Burhan Hakan Kanat, MD²; Fatih Mehmet Yazar, MD; Nizamettin Kutluer, MD²; Ayșe Azak Bozan, \\ MD³; Ali Aksu, MD²; Ömer Faruk Boran, MD $^{4}$; Özlem Güler, MD $^{5}$

\begin{abstract}
'Department of Surgery, Faculty of Medicine, Kahramanmaraş Sütçü İmam University, Kahramanmaraş, Turkey
${ }^{2}$ Department of Surgery, Elazig Training and Research Hospital, Turkish Ministry of Health, Medical Sciences University, Elazig, Turkey

${ }^{3}$ Department of Anesthesiology and Reanimation, Elazig Training and Research Hospital, Turkish Ministry of Health, Medical Sciences University, Elazig, Turkey

${ }^{4}$ Department of Anesthesiology and Reanimation, Faculty of Medicine, Kahramanmaraş Sütçü İmam University, Kahramanmaraş, Turkey

${ }^{5}$ Department of Emergency Medicine, Faculty of Medicine, Kahramanmaraş Sütçü İmam University, Kahramanmaraş, Turkey
\end{abstract}

\begin{abstract}
Background: Sclerosing encapsulating peritonitis (SEP) is a rare cause of acute abdomen and can be easily misdiagnosed. Preoperative diagnosis of the SEP can be performed with preoperative imaging studies. We aimed to evaluate the clinical features of ileus cases who were diagnosed with primary or secondary SEP in the last five years.

Methods: This retrospective cohort study evaluated the patients who were admitted with ileus or acute abdomen symptoms to the Emergency Department of Elazığ Training and Research Hospital and underwent surgery by the same surgical team of General Surgery Department between January 2014 and January 2019. Patients who were diagnosed with primary or secondary SEP were included. The demographic data, clinical presentation, whether the disease was primary or secondary, the treatment options performed and mortality rates were evaluated.

Results: SEP was observed in 11 of the patients. Ten patients underwent surgery $(90.9 \%)$, and one patient $(9.1 \%)$ was treated conservatively. Of the patients, six had secondary SEP (54.5\%) and five had primary SEP $(45.5 \%)$. In total, five patients were female $(45.5 \%)$ and six were male $(54.5 \%)$. The median age of the patients was 35 years (24-69). The median age of the patients with primary disease was 48 (29-69) years, while the median age of patients with secondary disease was 34.5 (24-64) years. One patient expired in the postoperative 8th hour.

Conclusion: SEP should be considered in the case of recurrent abdominal pain attacks, especially in patients undergoing peritoneal dialysis, and it should be known that the mortality rate is high when misdiagnosed.

Keywords: Abdominal cocoon syndrome, Acute abdomen, Sclerosing encapsulating peritonitis, Syndrome peritoneal dialysis

Cite this article as: Bozan MB, Kanat BH, Yazar FM, Kutluer N, Azak Bozan A, Aksu A, et al. A diagnostic dilemma for acute abdomen: sclerosing encapsulating peritonitis (abdominal cocoon syndrome); a retrospective cohort study. Arch Iran Med. 2021;24(6):447-452. doi: 10.34172/aim.2021.64
\end{abstract}

Received: June 1, 2020, Accepted: October 3, 2020, ePublished: June 1, 2021

\section{Introduction}

Sclerosing encapsulating peritonitis (SEP) is a condition characterized by encasement of the intestines and abdominal organs by fibrocollagenous band. It manifests in two different clinical forms: primary with an unknown origin and secondary due to other diseases. ${ }^{1}$ The clinical features of the disease are non-specific, such as recurrent acute and subacute small intestinal obstruction. These symptoms cover a broad spectrum, from recurrent ileus (nausea, vomiting) to acute abdomen due to complications (intestinal perforation or necrosis). It is usually difficult to diagnose the disease preoperatively. ${ }^{1,2}$ It is frequently diagnosed during surgical exploration.

SEP can be identified as the primary form without any underlying cause (abdominal cocoon syndrome, ACS) or the secondary form which may be related to abdominal surgical interventions, intraabdominal infections, chronic peritoneal dialysis, liver transplantation, ventriculoperitoneal shunt, and some drugs., ${ }^{3,4}$ The primary form is more common than the secondary form. ${ }^{5}$ The idiopathic/primary SEP was first described at the end of the nineteenth century and as primary SEP in the beginning of the 20th century, while the secondary SEP was first described by Gandhi et al in $1980 .{ }^{6-8}$ After Gandhi et al described the first etiology of secondary SEP as ambulatory peritoneal dialysis catheter usage, different causes of secondary SEP have been identified. The causes of secondary SEP include different types of diseases 
(peritoneal sarcoidosis, cirrhosis, familial Mediterranean fever, systemic lupus), previous surgery (liver and kidney transplantation, shunt surgery), peritoneal infections (tuberculosis, pelvic inflammatory disease), ambulatory peritoneal dialysis catheter, asbestosis exposure, in-vitro fertilization gastrointestinal malignancies, intraperitoneal chemotherapy and various drugs (Beta blockers - practolol, timolol, propranolol, other drugs - methotrexate ).,8-14

In this study, we aimed to evaluate the clinical features and the treatment options of patients who were diagnosed with primary (ACS) or secondary sclerosing encapsulation syndrome, in differentiation from other causes of ileus and acute abdomen.

\section{Materials and Methods}

This retrospective cohort study was conducted to evaluate the patients who were diagnosed with ACS or sclerosing encapsulation peritonitis (SEP) as a result of exploration or preoperative imaging technique - plain films, ultrasound evaluation, computed tomography (CT) were applied for relevant patients) for ileus by the same surgical team between January 2014 and January 2019 in a tertiary General Surgery Center in Elazig Training and Research Hospital. Our tertiary center has 28 service beds and 8 intensive care unit beds and approximately 1000 emergency and 250 ileus patients are followed up annually. Informed consent was obtained from the patients and they were informed that their preoperative and intraoperative images could be used for the study. Ethical approval was not obtained because of the retrospective character of the study. All procedures performed in studies involving human participants were in accordance with the ethical standards of the institutional and/or national research committee and with the 1964 Helsinki declaration and its later amendments or comparable ethical standards.

Inclusion criteria: Patients who were diagnosed with total or partial SEP intraoperatively or preoperatively according to diagnostic imaging techniques.

Exclusion criteria: Patients who underwent operation due to acute abdomen which was not caused by SEP, patients who suffered from different type of ileus and patients whose data could not be obtained.

The data were obtained by reviewing discharge notes, intensive care cards, patient clinical observation forms and operative notes in the electronical data system. Nine patients with primary or secondary SEP whose data could be obtained were included in the study. The demographic data (age, gender), clinical presentation of patients on admission, whether the disease was primary or secondary, the treatment performed (surgical procedures, conservative treatment) and mortality rates were evaluated.

Statistical Package for Social Sciences (SPSS) IBM 20.0 was used for statistical analysis. For demographic identification of the patients, the quantitative data were presented as median (minimum - maximum values) and the categorical data were expressed as number (n) and percentage $(\%)$.

\section{Results}

In our study, 1090 patients have been followed up for ileus within the last 5 years and of these patients, 421 underwent surgery. SEP was observed in 11 of the patients. Ten patients underwent surgery (90.9\%), while one patient was followed up conservatively (9.1\%) with stopping oral intake, fluid replacement, and nasogastric decompression. Of these patients, six had secondary SEP (54.5\%) and five had primary SEP (abdominal cocoon syndrome) (45.5\%). The underlying etiological causes of the secondary SEP were surgical treatment of hydatid cyst of liver (segment 6), previous gynecologic operation (total abdominal hysterectomy and bilateral salphingoopherectomy) and use of peritoneal dialysis catheter due to chronic renal failure (As shown in Table 1). Of these patients, five were female (45.5\%) and six were male (54.5\%).

The median age of the patients was 35 years (24-69 years). The median age of male patients was 33 years (29-69 years), while the median age of female patients was 46 years (24-64 years). The median age of the patients with primary disease was 48 years (29-69 years), while the median age of patients with secondary disease was 34.5 years (24-64 years). One patient who underwent right hemicolectomy passed away due to sepsis in the 8th postoperative hour.

Ten patients were diagnosed intraoperatively (Figures 1 and 2) and the preoperative imaging modalities were plain graphies, ultrasonographic (US) evaluation, and CT (Figures 3 and 4). One of the preoperatively diagnosed patient was treated conservatively and the other was operated due to acute abdomen.

The causes of acute abdomen in patients who underwent surgery were ectopic pregnancy rupture for one patient, small intestine perforation for three patients and ileus for six patients. One patient was treated conservatively. The reasons for admission to the clinic, preoperative diagnostic tests, treatment methods, demographic data (age, type of disease), mortality and etiologic causes are shown in Table 1.

\section{Discussion}

SEP, also known as sclerosing peritonitis, encapsulation peritonitis, or peritonitis chronica fibrosa incapsulata, is a rare manifestation of ileus that has two types: primary (idiopathic, more commonly known as ACS) and secondary. ${ }^{1}$ Although primary SEP was observed in adolescent female patients in the past, as it may be seen in this study, nowadays, also young adult males suffer from this syndrome. ${ }^{1,12}$ In our study, previous gynecologic operation, ambulatory peritoneal dialysis catheter and surgical treatment of hydatid cyst were observed to be the causes of secondary SEP.

Another classification of SEP involves three groups. In type 1 SEP, a small section of the small bowel is surrounded by a fibrous capsule; in type 2 , the entire small bowel is 
Table 1. Demographic Data of the Patients.

\begin{tabular}{|c|c|c|c|c|c|c|c|c|}
\hline Patient & Gender & Age & $\begin{array}{l}\text { Diagnostic } \\
\text { Test }\end{array}$ & Type & Treatment & Mortality & Etiology & Clinic \\
\hline 1 & Female & 35 & US & Secondary & $\begin{array}{l}\text { Primary suture to intestine }+ \\
\text { excision of capsule }\end{array}$ & No & $\begin{array}{l}\text { Operated liver } \\
\text { hydatid cyst } \\
\text { (segment 6) }\end{array}$ & $\begin{array}{l}\text { Ectopic pregnancy } \\
\text { rupture + acute } \\
\text { abdomen }\end{array}$ \\
\hline 2 & Male & 48 & $\mathrm{CT}$ & Primary & $\begin{array}{l}\text { Partial intestinal excision + } \\
\text { excision of capsule }\end{array}$ & No & Idiopathic & $\begin{array}{c}\text { Intestinal } \\
\text { perforation + } \\
\text { acute abdomen }\end{array}$ \\
\hline 3 & Male & 32 & $\mathrm{CT}$ & Primary & $\begin{array}{l}\text { Laparoscopic exploration + } \\
\text { excision of capsule }\end{array}$ & No & Idiopathic & Acute abdomen \\
\hline 4 & Female & 24 & $\begin{array}{l}\text { US } \\
\text { CT }\end{array}$ & Secondary & $\begin{array}{l}\text { Primary suture to intestine }+ \\
\text { Excision of capsule }\end{array}$ & No & $\begin{array}{c}\text { Peritoneal } \\
\text { dialysis catheter }\end{array}$ & Ileus \\
\hline 5 & Male & 69 & $\mathrm{CT}$ & Primary & Excision of capsule + bridectomy & No & Idiopathic & Ileus \\
\hline 6 & Male & 29 & $\begin{array}{l}\text { Plain Graphy } \\
\text { CT }\end{array}$ & Primary & $\begin{array}{l}\text { Right hemicolectomy + end to } \\
\text { side ileotransverse anastomosis }\end{array}$ & Yes & Idiopathic & Ileus \\
\hline 7 & Male & 34 & $\mathrm{CT}$ & Secondary & $\begin{array}{l}\text { Primary suture to intestine }+ \\
\text { excision of capsule }\end{array}$ & No & $\begin{array}{c}\text { Peritoneal } \\
\text { dialysis catheter }\end{array}$ & $\begin{array}{l}\text { Intestinal } \\
\text { perforation + } \\
\text { acute abdomen }\end{array}$ \\
\hline 8 & Female & 61 & $\mathrm{CT}$ & Primary & Excision of capsule + bridectomy & No & Idiopathic & Ileus \\
\hline 9 & Male & 31 & CT & Secondary & Medical therapy & No & $\begin{array}{c}\text { Peritoneal } \\
\text { dialysis catheter }\end{array}$ & Ileus \\
\hline 10 & Female & 46 & $\begin{array}{l}\text { Plain Graphy } \\
\text { CT }\end{array}$ & Secondary & $\begin{array}{l}\text { Primary suture to intestine }+ \\
\text { excision of capsule }\end{array}$ & No & $\begin{array}{c}\text { Peritoneal } \\
\text { dialysis catheter }\end{array}$ & $\begin{array}{c}\text { Intestinal } \\
\text { perforation }+ \\
\text { acute abdomen }\end{array}$ \\
\hline 11 & Female & 64 & US & Secondary & Excision of partial capsulation + & No & $\begin{array}{l}\text { Previous } \\
\text { gynecologic } \\
\text { surgery }\end{array}$ & Ileus \\
\hline
\end{tabular}

US, Ultrasonographic evaluation; CT, Computed tomography.

encapsulated by a fibrous capsule, and in type 3, the entire small bowel and other organs are encapsulated by a fibrous capsule. ${ }^{15}$ All of our operated patients were type 2 .

ACS is seen frequently in tropical and subtropical regions, such as China, India and Turkey, and idiopathic ACS is reported more common in women than men according to the published recent studies. ${ }^{11}$ On the other hand, male patients and secondary SEP were slightly higher compared to the literature. This difference cannot change the knowledge about the disorder but it can warn us to be more careful about secondary forms and male patients. ${ }^{1,3}$

The secondary form may result from different etiological pathologies. After a report by Gandhi et al introduced ambulatory peritoneal dialysis catheter as a cause of secondary SEP, different etiologic pathologies have been reported in case reports and case series. ${ }^{8}$ Any type of abdominal surgery may result in SEP, such as kidney transplantation, liver transplantation, and HIPEC. ${ }^{13,17,18}$ Additionally intraabdominal granulomatous infections such as tuberculosis, pelvic inflammatory diseases, medical treatment for different cardiac disorders such as propranolol, and malignancies may lead to the secondary form of SEP. ${ }^{4,18-22}$

Although the incidence of ACS is not exactly known, the incidence and prevalence of secondary SEP are $0.7 \%-3.3 \%$ and $0.54 \%-7.3 \%$, respectively, in patients with peritoneal dialysis catheter. ${ }^{16,23}$ Our results show the clinical incidence for primary SEP at $0.46 \%$ and for secondary SEP at $0.55 \%$.

The clinical symptoms may be of acute onset, as in our patients who underwent surgery, or may manifest as subacute recurrent, as in our conservatively treated patient. ${ }^{1,23}$ In our study, abdominal pain was the most common clinical symptom (100\%). Nausea, vomiting and abdominal pain due to complete and partial obstruction of the intestine are among the symptoms that may frequently arise. Anorexia may be seen due to nutritional problems. Physical examination has no characteristics. In the presence of a condition leading to acute abdomen, such as necrosis and perforation, abdominal tenderness may be observed, as in the patients who underwent surgery in our study. It may also manifest as a palpable mass since the abdominal organs are covered by a fibrocollagenous band on one side. ${ }^{23}$

On plain graphies, as an initial diagnostic method, the intestinal loops may be observed as conglomerated in the center or laterally. ${ }^{24}$ In imaging techniques with barium, conglomerated intestinal loops with a cauliflower-like appearance and prolonged passage time are observed. However, barium enhanced graphies should not be used under emergency conditions because of the risk of perforation. $^{25}$

Although ultrasonography is an inexpensive, fast technique that can be performed everywhere, it depends on the radiologist's experience. Dilated intestinal loops 


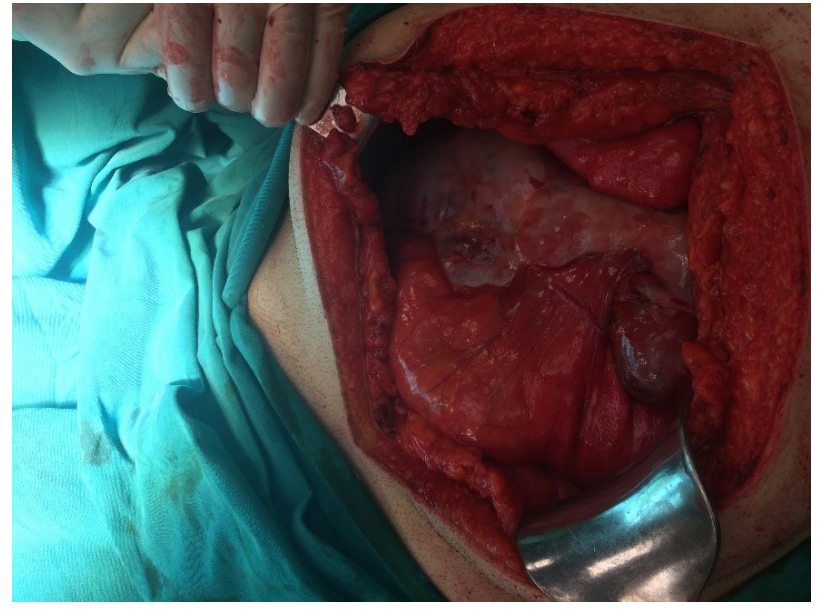

Figure 1. Operative view of the complete secondary sclerosing encapsulating peritonitis case caused by peritoneal dialysis catheter.

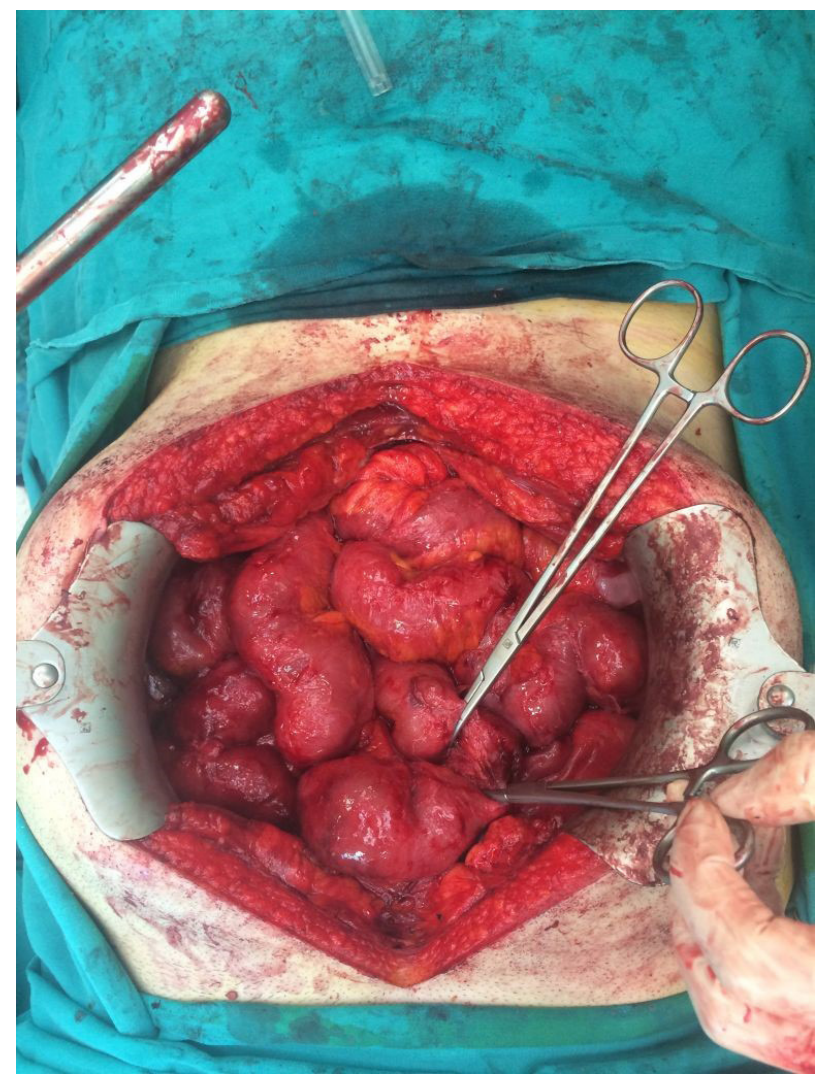

Figure 2. Intestinal structures after decapsulation of the case in Figure 1 (perforation area due to necrosis of intestine is seen between surgical clamps).

surrounded by fluid-filled fibrous band, thickened peritoneal wall and free fluid can be visualized. ${ }^{26}$ However, in many cases as in our patients, it cannot identify the pathology due to dilated intestines.

CT emerges as a fast and more sensitive diagnostic technique in patients for whom the use of contrast agent is not contraindicated. It has an important place in the differential diagnosis, especially under emergency conditions. As it may be observed on the tomographic images of our patients, the intestinal loops are covered by a thick fibrous membrane, and edema and free fluid may be observed in the intestinal wall. Moreover, peritoneal and mesenteric thickening and peritoneal calcifications

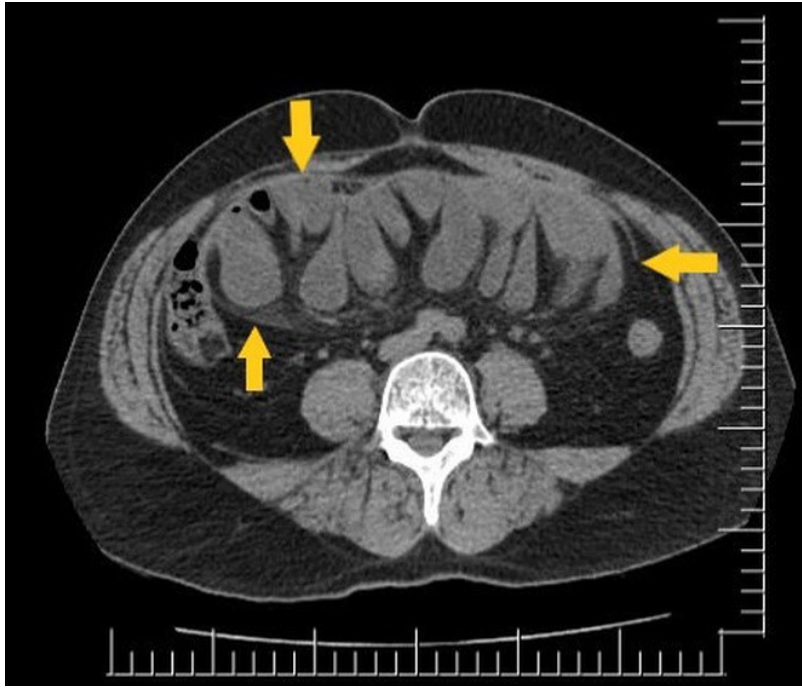

Figure 3. Preoperative computed tomographic view of the patient in figure 1 and 2 (Yellow Arrows: Formation of Sclerating Capsule).

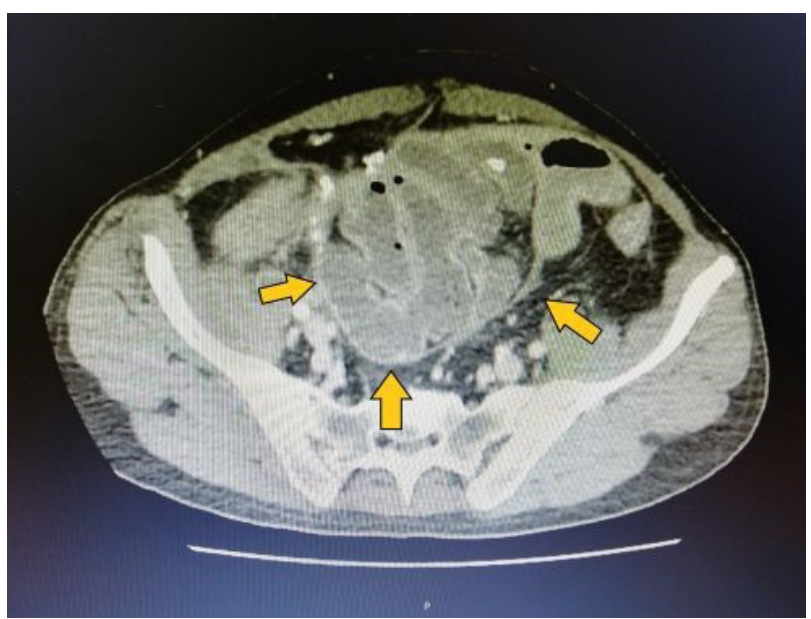

Figure 4. Preoperative computed tomographic view of the complete abdominal cocoon syndrome (primary SEP) case.

may be detected (as shown in Figure 1). ${ }^{27}$ As our patients were diagnosed intraoperatively and CT findings were understood after reevaluation, clinical suspicion of the pathology is more important for preoperative diagnosis of acute abdomen, especially for the patients who use ambulatory peritoneal dialysis catheter. In addition, CT can be the first step of differential diagnostic tests for these patients.

Magnetic resonance imaging (MRI) and FDG-positron emission tomography (PET), which has recently started being used especially in metastatic tumor screening, are among the other diagnostic methods. ${ }^{28}$ MRI and PET cannot be used in the emergent conditions. Additionally, PET cannot be preferred for the patients without any malignancy because of the limitations of our health payment rules according to our Ministry of Health's comments. Moreover, these imaging modalities are expensive diagnostic tests.

The preoperative diagnosis is possible only in the presence of clinical suspicion. However, most of the cases are diagnosed during intraoperative exploration, 
as in our surgical cases. In the retrospective evaluation of our patients after being diagnosed in the intraoperative period, sclerosing capsule formation surrounding the intestinal loops was detected when preoperative computed tomographic images were re-evaluated after surgical diagnosis.

Although the majority of the patients are diagnosed intraoperatively, as in our patients who underwent surgery, if the patient does not manifest the findings of acute abdomen, as in our 9th patient, they can be treated conservatively (with stopping oral intake, nasogastric decompression, total parenteral nutrition) and drugs (colchicine, steroids, immunosuppressive drugs such as azathioprine). ${ }^{19}$ Medical treatment can be used to prevent encapsulation, especially in patients with peritoneal dialysis catheter who are at high risk for secondary SEP. ${ }^{17}$ Additionally, as a result of tubercular abdominal infections, abdominal cocoon cases can be treated medically with antitubercular therapy. ${ }^{19,21}$ In undiagnosed patients who develop acute abdomen, surgical treatment should be considered. In addition to the procedures performed via open surgery, laparoscopic surgery can also be used for surgical treatment. Adhesions are released and the encapsulation is decorticated, as in our patients. Resection anastomosis should be avoided unless there is evidence of necrosis since the risk of anastomotic leak increases in such patients (Figures 2, 3 and 4).,25,29 Conservative methods and medical therapies can be preferred in the postoperative treatment period. ${ }^{25}$ On pathologic evaluation, fibroconnective tissue proliferation, inflammatory infiltrates and dilated lymphatics, with no evidence of foreign body granulomas, giant cells or birefringent material on the peritoneal tissue are noted. ${ }^{14}$ Membrane shows thickened vascular fibrocollagenous tissue, with or without chronic inflammatory reaction evidenced by lymphocytic and plasma cell infiltrates. In tubercular SEP, caseating epithelioid cell granulomas were seen in the membrane, although acid fast bacilli could not be demonstrated. ${ }^{30}$

The mortality rate ranges from $0 \%$ to $71 \%$. As in our secondary SEP patient who passed away, the mortality rate increases especially in peritoneal dialysis patients. Recurrence may occur due to adhesions at a rate of $6 \%-29 \%$. In the short term, the risk of early obstruction is more significant $(8.7 \%-66.7 \%)$. In the long term, if resection has been performed, short bowel syndrome and associated anemia, vitamin deficiencies (B12) and fat absorption disorders may develop. ${ }^{31}$

The most important limitation of our study is its retrospective nature. However, the number of cases for this pathology can be helpful for understanding the characteristics of this rare disorder. Additionally, the number of secondary cases was higher than the primary form. This can be explained by the increased use of ambulatory peritoneal dialysis catheter.

In conclusion, SEP is a rare disease which is difficult to diagnose in the preoperative period unless there is a clinical suspicion. It should be kept in mind in the case of recurrent abdominal pain attacks, especially in patients undergoing peritoneal dialysis. CT should be the first diagnostic technique. It should be remembered that the mortality rate is high when misdiagnosed or when the diagnosis of the patient is delayed.

\section{Authors' Contribution}

MBB, FMY and BHK: Conception and design, methodology and supervision. $\mathrm{AAB}, \mathrm{OFB}, \mathrm{MBB}, \mathrm{NK}$ and $\mathrm{AA}$ : Analysis and interpretation. $\mathrm{MBB}, \mathrm{AAB}, \mathrm{NK}$ and OG: Preparation of Paper original draft. MBB, FMY, BHK, AA and NK: Resources. All authors cooperate in review, editing and approving the final version.

\section{Conflict of Interest Disclosures}

The authors declare that they have no conflicts of interest.

\section{Ethical Statement}

Data contents and the diagnostic imaging modalities doesn't inlude any personal information of the patients.

\section{References}

1. Akbulut S. Accurate definition and management of idiopathic sclerosing encapsulating peritonitis. World J Gastroenterol. 2015;21(2):675-87. doi: 10.3748/wjg.v21. i2.675.

2. Sharma D, Nair RP, Dani T, Shetty P. Abdominal cocoon-a rare cause of intestinal obstruction. Int J Surg Case Rep. 2013;4(11):955-7. doi: 10.1016/j.ijscr.2013.08.004.

3. Çolak Ş, Bektaş H. Abdominal cocoon syndrome: a rare cause of acute abdomen syndrome. Ulus Travma Acil Cerrahi Derg. 2019;25(6):575-9. doi: 10.14744/ tjtes.2019.48380.

4. Banday M, Rauof S. Secondary encapsulating peritonitis: a study of cases over five years. Turk J Surg. 2019;35(3):171-7. doi: 10.5578/turkjsurg.4143.

5. Kanat BH, Yazar FM, Bozan MB, Özkan Z, Erol F, Bilgiç Y. Abdominal koza sendromu: iki olgu sunumu. Okmeydanı Tip Derg. 2014;30(3):173-5. doi:10.5222/otd.2014.173. [Turkish].

6. Cleland J. On an abnormal arrangement of the peritoneum, with remarks on the development of the mesocolon. J Anat Physiol. 1868;2(2):201-6.

7. Owtschinnikow PJ. Peritonitis chronica fibrosa incapsulata. Arch Klin Chir. 1907;83:623-34.

8. Gandhi VC, Humayun HM, Ing TS, Daugirdas JT, Jablokow VR, Iwatsuki S, et al. Sclerotic thickening of the peritoneal membrane in maintenance peritoneal dialysis patients. Arch Intern Med. 1980;140(9):1201-3.

9. Toma EA, Giulea C, Enciu O, Calu V, Miron A. Peritoneal encapsulation-a rare cause of small bowel obstruction. Chirurgia (Bucur). 2019;114(2):290-4. doi: 10.21614/ chirurgia.114.2.290.

10. Renko AE, Mirkin KA, Cooper AB. Peritoneal encapsulation: a rare cause of small bowel obstruction. BMJ Case Rep. 2019;12(4). doi: 10.1136/bcr-2018-228594.

11. Machado NO. Sclerosing encapsulating peritonitis: review. Sultan Qaboos Univ Med J. 2016;16(2):e142-51. doi: 10.18295/squmj.2016.16.02.003.

12. Yuce E, Akgun N, Altındis Bal A, Namli Kalem M, Bayrak 
R, Duvan CI. A case of twin IVF pregnancy complicated with sclerosing encapsulating peritonitis diagnosed at caesarean delivery. J Obstet Gynaecol. 2018;38(7):1018-20. doi: 10.1080/01443615.2017.1399259.

13. Caicedo L, Delgado A, Caicedo LA, Bravo JC, Thomas LS, Rengifo M, et al. Sclerosing encapsulated peritonitis: a devastating and infrequent disease complicating kidney transplantation, case report and literature review. Int J Surg Case Rep. 2017;33:135-8. doi: 10.1016/j.ijscr.2017.02.048.

14. Puppala R, Sripathi S, Kadavigere R, Koteshwar P, Singh J. Abdominal cocoon secondary to disseminated tuberculosis. BMJ Case Rep. 2014;2014. doi: 10.1136/bcr-2013-202568.

15. Akbas A, Hacım NA, Dagmura H, Meric S, Altınel Y, Solmaz A. Two different clinical approaches with mortality assessment of four cases: complete and incomplete type of abdominal cocoon syndrome. Case Rep Surg. 2020;2020:4631710. doi: 10.1155/2020/4631710.

16. Liberale G, Sugarbaker PH. Sclerosing encapsulating peritonitis as a potential complication of cytoreductive surgery and HIPEC: clinical features and results of treatment in 4 patients. Surg Oncol. 2018;27(4):657-62. doi: 10.1016/j.suronc.2018.08.005.

17. Aliyev V, Yagi S, Hammad A, Badawy A, Sasaki Y, Masano $\mathrm{Y}$, et al. Sclerosing encapsulating peritonitis after livingdonor liver transplantation: a case series, Kyoto experience. Ann Hepatobiliary Pancreat Surg. 2018;22(2):144-9. doi: 10.14701/ahbps.2018.22.2.144.

18. Danford CJ, Lin SC, Smith MP, Wolf JL. Encapsulating peritoneal sclerosis. World J Gastroenterol. 2018;24(28):3101-11. doi: 10.3748/wjg.v24.i28.3101.

19. Singh H, Irrinki S, Yadav TD, Kumar H, Kharel J, Dhaka N, et al. Surgical outcomes in patients with abdominal cocoon: series of 15 patients. World J Surg. 2019;43(9):2143-8. doi: 10.1007/s00268-019-05006-x.

20. Sharma V, Mandavdhare HS, Rana SS, Singh H, Kumar A, Gupta R. Role of conservative management in tubercular abdominal cocoon: a case series. Infection. 2017;45(5):6016. doi: 10.1007/s15010-017-1012-5.

21. Noh SH, Ye BD, So H, Kim YS, Suh DJ, Yoon SN. Sclerosing encapsulating peritonitis in a long-term propranolol user. Intest Res. 2016;14(4):375-8. doi: 10.5217/ir.2016.14.4.375.
22. Shah MY, Gedam BS, Sonarkar R, Gopinath KS. Abdominal cocoon: an unusual cause of subacute intestinal obstruction. Indian J Surg. 2013;75(Suppl 1):391-3. doi: 10.1007/s12262012-0582-9.

23. Kirshtein B, Mizrahi S, Sinelnikov I, Lantsberg L. Abdominal cocoon as a rare cause of small bowel obstruction in an elderly man: report of a case and review of the literature. Indian J Surg. 2011;73(1):73-5. doi: 10.1007/s12262-0100200-7.

24. Ndiaye AR, Mbengue A, Soko TO, Diémé EP, Diagne NM, Diouf CT, et al. Idiopathic sclerosing encapsulating peritonitis: a case in an adolescent girl. Diagn Interv Imaging. 2012;93(7-8):629-31. doi: 10.1016/j.diii.2012.03.017.

25. Solak A, Solak İ. Abdominal cocoon syndrome: preoperative diagnostic criteria, good clinical outcome with medical treatment and review of the literature. Turk J Gastroenterol. 2012;23(6):776-9. doi: 10.4318/tjg.2012.0500.

26. Karl AP, Leebmann H, Zorger N. Abdominal cocoon syndrome. Dtsch Arztebl Int. 2019;116(27-28):486. doi: 10.3238/arztebl.2019.0486b.

27. Jovani M, Baticci F, Bonifacio C, Omodei PD, Malesci A. Abdominal cocoon or idiopathic encapsulating peritoneal sclerosis: magnetic resonance imaging. Dig Liver Dis. 2014;46(2):192-3. doi: 10.1016/j.dld.2013.08.136.

28. Vadi SK, Mittal BR, Parihar AS, Kumar R, Sharma V, Mandavdhare HS. Demonstration of tubercular "abdominal cocoon" (sclerosing encapsulating peritonitis) in 18F-FDG PET/CT. Clin Nucl Med. 2018;43(10):771-2. doi: 10.1097/ rlu.0000000000002238.

29. Arif SH, Mohammed AA. Abdomen cocoon causing chronic abdominal pain and intestinal obstruction; a case series. Ann Med Surg (Lond). 2019;48:7-10. doi: 10.1016/j. amsu.2019.10.003.

30. Rastogi R. Abdominal cocoon secondary to tuberculosis. Saudi J Gastroenterol. 2008;14(3):139-41. doi: 10.4103/1319-3767.41733.

31. Li M, Zhu W, Li Y, Jiang J, Li J, Li N. Long intestinal tube splinting prevents postoperative adhesive small-bowel obstruction in sclerosing encapsulating peritonitis. BMC Gastroenterol. 2014;14:180. doi: 10.1186/1471-230x-14180. 